\title{
Growth of nursing education sector and its effects on professionalization of nurses in Nepal
}

\author{
Subedi, Deena Rai* \\ $R N, M P H$ \\ Nursing and Public Health Professional
}

\begin{abstract}
This paper traces historical development and growth of the nursing sector in Nepal and then explores the impacts and effects of the growth to the nursing sector and nurses' professionalization. Providing an overview of an evolutionary development of the nursing sector in three historical junctures, "formative period", "transformative period" and "globalised period", this paper shows that historically nursing education in Nepal has grown extensively in the globalised period, after 1990 when the government allowed the private sector to open nursing colleges. Despite the growth in the sector, this paper shows that privatisation of nursing education sector has not been accompanied by strong monitoring and quality control mechanisms. As a result, it has had several implications to professionalization of nursing service in the country. The impacts noticed are 1) privatisation and commercialisation of nursing education and training sector; 2) problems of quality control and integrity; 3) lack of demand and supply analysis of nursing professionals; 4) exploitation of newly trained nurses; and 5) Nursing as an accelerator of international migration.
\end{abstract}

Key words: Nursing, education, service, professionalization, migration, Nepal

\section{Introduction}

Nursing care is an integral part of health service delivery in hospitals, care homes as well as community. Due to globalisation of technology and innovations in health sciences, health service delivery has become an integrated service sector(WHO, 2003) in which role of nursing is critically important. Indeed, nursing as caring can serve as the foundation for the successful and substantive integration of care system(Boykin \& Schoenhofer, 2001).

In the context of Nepal, health sector has significantly modernised in the last several decades(Dixit, 2005). Alongside of rapid changes and development in the health sector, the nursing sector $^{1}$ has also gone through massive changes and transformation, both in terms of nursing education and nursing care delivery. A retrospective view suggests that nursing care in Nepal was developed simultaneously with the development of health system in the country. Although modern health system was introduced formally after establishment of Bir Hospital, the first hospital in the country, in July 1889, the health system in Nepal was in a primitive stage until late 1970s.

What started as a humanitarian and self-less service dedicated to sick and needy people, nursing profession has, over the time, been professionalised, but also commercialised. In the changed context in Nepal, a liberal market economy policy was introduced in early 1990s (Khanal, Rajkarnikar, Acharya, \& Upreti, 2005). With this policy change, the health sector also experienced the effects of marketization. As a result, the nursing sector also changed accordingly, with nursing training and education being delivered by the private sector. While the internal economic policy was a contributing factor for privatisation of nursing sector, the need of well qualified nurses in developed countries further became a catalytic factor for booming nurse producing industry in a developing country like Nepal (Gurung \& Facchini, 2011; Subedi, 2012).This changing context leads us to make such question as how much the domestic health sector has benefitted from the growth of the nursing education sector and what effects the change might have in professionalization of the nursing sector itself. It also points to the question like whether the current upsurge in nurse production has been really absorbed by the health sector in the country.

This article explores historical junctures in terms of development in nursing education and nursing service delivery. Following an historical overview of the growth of the nursing sector, it further examines the effects that the growth has had on overall nursing sector and nurses' professionalization. Although Nepal has a rich history of nursing profession, the literature on the current issues and problems faced by the nursing sector is very limited. This paper also aims to address this gap.

\footnotetext{
*raisubedina@gmail.com

${ }^{1}$ The term 'nursing sector' here refers to both nursing education/training sector and nursing care delivery sector.
} 
Section two provides a brief methodology. The third section describes historical description of development of nursing education and service in the country. The fourth section analyses current issues and challenges facing the nursing sector. The last section provides summary and conclusion of this article.

\section{Methodology}

This paper is based on interviews and consultations conducted by the author with professional nurses in Kathmandu and Biratngar in Nepal in2010. A total of twenty interviews were conducted during this period. A follow up phone interviews were conducted with seven nurses from Kathmandu in March and April 2014. In addition to interviews, this paper also utilises reflective analysis, using the author's personal experience and reflections of having worked as hospital and community nurse in Nepal between 1996 and 2010. To update the data, Information from newspapers and governmental and non-governmental organisations' reports are also included.

\section{Nursing in Nepal: Historical overview of the growth}

Based on how nursing training and education was developed as part of health service system in the country, the history of the nursing sector in Nepal can be divided into three junctures: formative period, transformative period and globalised period.

\section{Formative period}

The formative period of nursing sector in the country dates the period prior to 1970s. Nepal was ruled by the Rana Oligarchy between 1846 and 1951. The Rana regime was a dark period in the history of development. Nonetheless, some progress was made in terms of laying a foundation for modern health system in the country. For example, in July 1889, Rana Prime Minister BirShamsher established Bir Hospital, the first hospital in the country. Following this, the hospital authorities realized the need for nurses and midwives to provide care to hospital patients. As a result, four Nepalese girls were sent to India for an 18 month midwifery courses. According to Sigdel(2011), Ms. Uma Devi Das and Ms. Rukmini Charan Shrestha were sent to India to study registered Nurses in the year 1952 and this was possible due to the scholarships provided by the World Health Organisation, (2009 BS) ${ }^{2}$. Upon their return, Ms. Uma Devi Das and Ms. Rukmini Charan Shrestha became the first registered nurse in the country. A group of eight Nepali girls were sent to India for midwifery diploma training in the year 1953. Prior to establishment of the Bir Hospital and before sending Nepali girls for nursing training in India, nursing was not recognised as profession.

Paropakar Maternity and Women's Hospital, Thapathali, Kathmandu, popularly known as Prasuti Griha, was established in August 1959. It was this maternity hospital where the India-trained midwives were employed as nurse. In the same year when PrasutiGriha was established, first nursing college in the country was established in Lalitpur district in the Kathmandu valley. The college was later moved to Maharajgunj hospital and presently it is knows as Nursing Campus Maharajgunj. In 1959, another school of nursing education was established in Lalitpur known as Shanta Bhawan School of Nursing. It was supported by the United Mission to Nepal (UMN).

It was in this formative period that the nursing sector began to grow outside the Kathmandu valley. For example, two other nursing training institutes that offered Auxiliary Nurse Mid-wife (ANM) training were established in Chitawan and Biratnagar in 1962 and 1969 respectively.

In the formative period, nursing education was not accessible to women from rural areas as the service was entirely Kathmandu-centric, with exception of ANM training centres in Bharatpur and Biratngar. Moreover, the nursing sector was entirely restricted to women. Several respondents in Kathmandu mentioned that while the opportunity was limited for nursing training/education in before 1970s, nursing was not seen as a very prestigious job in the community. Before 1970s, women's economic participation in the society was extremely low as women's world was basically confined within the household. Therefore, women, especially from the hierarchical Hindu families including Brahmins and Chettris in which women's position was mostly subordinated, were not easily allowed to join the nursing sector.

\section{Transformative period}

It can be stated that the transformative period roughly begins after 1970s when the education sector was modernised. This period can be characterised by two key features: upgrading of education/training and diversification of nursing sector.

First, in early 1970s, there was a major breakthrough in upgrading of the nursing education system in the country. For instance, in 1972 all academically running nursing schools were placed under Tribhuvan

${ }^{2}$ BS refers to BikramSambat, the date format the follows lunar calendar and it is official format of writing date in Nepal. 
University Institute of Medicine (Sigdel, 2011). As a result, the nursing school running at that time had automatically fallen under the umbrella of the nation's only university - Tribhuvan University. This was a major transformation. Furthermore, quantitative progress also occurred in this period. For example, ANM extension campus in Tansen, Palpa district and Chhetrapati, Kathmandu were opened respectively(Sigdel, 2011).

It was during this period that the Proficiency Certificate Nursing (PCL) nursing curriculum under TU programme was introduced. The PCL nursing is a three year diploma course that is aimed at producing Registered Nurses (RN) in Nepal. As the curriculum was upgraded, the entry requirement also changed. For example, initially, in the formative period, a perspective ANM candidate would need to have completed year eight. This was changed later with the new requirement for ANM was year 10 or equivalent. Under new curriculum, basic eligibility for PCL nursing was completion of School Leaving Certificate (SLC).

Similarly, Bachelor of Nursing (BN), a two year graduation programme in nursing and midwifery, was introduced in 1977. With this advance degree available for RNs, albeit in limited numbers, it marked another remarkable sign of transformation of nursing education sector in the country. More specialised forms of nursing such as community nursing, adult nursing and paediatric nursing were introduced in the $1980 \mathrm{~s}^{3}{ }^{3}$

Secondly, nursing education and service was also diversified into two specialised areas: hospital nursing and community nursing. The Bachelor of Nursing curriculum clearly made provisions for specialisation in these areas. In the meantime, it was in this formative period that the nursing education was open for men as well. Inclusion of male gender in the nursing service was a major transformative step, although this decision was scrapped later; as a result nursing is considered to be a "deliberately gender biased profession in Nepal". ${ }^{4}$

As far as diversification of nursing is concerned, the social dimension is worth mentioning. According to many respondents who were trained in early 1970s reported that the nursing sector was becoming more socially diverse (meaning nurses coming from different caste and ethnic background) in 1980s. Although it was confessed by respondents that very few nurses were coming from marginalised social groups such as Dalits. Participation of nurses from Janajati (ethnic group) was reported well. Though no segregated data on caste dimension of nursing sector was available in 1980s, a majority of the nurses interviewed came from ethnic (Janajati) groups.

\section{Globalised period}

Nepal became a multi-party democracy in 1990. Following democratisation, the country not only became open to outer world and international migration and emigration increased exponentially (Subedi, 2012; Thieme \& Wyss, 2005). One important feature of post-1990 period is the privatisation policy which allowed the health sector to be privatised. As a result, number of private hospitals grew gradually across the country. This increased the demand of trained nurses in the country.

In terms of nursing education, a number new development occurred in this period. In 1993, BP Koirala Institute of Health Sciences was established in Dharan, Sunsari. BPKIHS had significant impact on development of health sciences in the country, including nursing education. For example, in 1996 Basic Bachelor of Science (BSc) Nursing, a four year program, was established in BPKIHS Dharan for the first time in the country. Similarly, BHKIHS also, for the first time, started the MSc Nursing Program (in Community and Psychiatry Nursing) in 2008. In 1995, Institute of Medicine (IOM) Maharjgunj teaching hospital started Master of Nursing (MN), a two year post-graduate programme for the first time in 1995.

Most remarkable development in this period is establishment of the Council for Technical Education and Vocational Training (CTEVT) in 1989. CTEVT is a national autonomous apex body of Technical and Vocational Education and Training (TVET) sector committed for the production of technical and skilful human resources required to the nation. It is mainly involved in policy formulation, quality control, preparation of competency based curriculum, developing skill standards of various occupations and testing the skills of the people, conduct various research studies and training needs assessment. CTEVT has developed a three year PCL nursing curriculum and currently this programme is delivered through two CTEVT run campuses and 77 affiliated colleges. In addition, CTEVT also has ANM programme which is offered through four CTEVT led colleges and 40 affiliated institutes.

After CTEVT introduced the PCL and ANM nursing programme, the private sector has been proactively involved in providing nursing education because significantly high numbers of CTEVT affiliated nursing colleges are run by the private sector, although some of them are also run by community hospital and cooperatives. Thus after establishment of CTEVT, the nursing education sector has been heavily privatised. The following table demonstrates different types of nursing programmes and number of colleges active in the country as of May 2014.

\footnotetext{
${ }^{3}$ Interview with a Nurse lecturer in Kathmandu.
}

${ }^{4}$ Interview with a Nurse lecturer in Biratnagar. 


\begin{tabular}{|l|l|c|}
\hline \multicolumn{1}{|c|}{ Nursing education programme } & \multicolumn{1}{c|}{ Duration of programme } & Number of college/campuses \\
\hline Auxiliary Nurse Midwife (ANM) & 18 months diploma & 48 \\
\hline Proficiency Certificate Level nursing & 3 years diploma & 101 \\
\hline Bachelor of Nursing (BN) & 2 years graduate programme & 21 \\
\hline Bachelor of Science (BSc) Nursing & 4 years graduate programme & 24 \\
\hline Master of Nursing (MN) & 2 years post-graduate programme & 4 \\
\hline
\end{tabular}

Source: Compiled by the author (2014).

Gurung and Facchini(2011) estimates that these nursing colleges produce approximately 4000 PCL graduated nurses annually, except ANM, BN and masters level nurses. According to Nepal Nursing Council, the authorised body that offers registration to nurses, a total of more than 27000 PCL nurses are registered as of January 2014. As shown in the table below, the total number of nurses in the country, including ANM and foreign nurses is more than 50,000.

\begin{tabular}{|l|c|}
\hline \multicolumn{1}{|c|}{ Category/type } & Total registered \\
\hline Registered Nurse ( those who have had nursing degrees above than PCL nursing & 27924 \\
\hline ANM & 21766 \\
\hline Foreign nurses & 780 \\
\hline Total & 50470 \\
\hline
\end{tabular}

Source: Nepal Nursing Council, July 2014.

As will be discussed later in this paper, the post-1990 juncture has become a globalised period because the nurses produced in the country have migrated abroad, to the developed country.

While the nursing sector in the country has grown drastically in the last five decades, and more rapidly in the last two decades, this growth has also brought about a number of critical issues and challenges to the forefront in the health sector. It has also raised concerns about professionalization of the nursing sector. The following section examines these critical issues.

\section{Implication to the nursing sector and nurses' professionalization}

\section{Privatisation of nursing sector}

One visible impact of growth of the nursing sector is commercialisation of nursing education. When the CTEVT introduced PCL nursing and ANM curriculum together with other health related nursing curriculum such as Proficiency Certificate in Medical Lab Technology, Proficiency Certificate in Radiography, Proficiency Certificate in Ayurvedic Science, Diploma in Pharmacy, Diploma in Dental Science and Diploma in Ophthalmic Science, this provided a lucrative opportunity for the private sector to invest in health education. This new developed that occurred in early 1990s broke the government's monopoly in delivering health related education including nursing education and created the private sector as champion in the health sector. While this development is considered good in terms of advancing the health sector in the country, some interviewees cautioned that entry of the private sector has hugely commercialised the nursing sector. According the information provided by several nurse teachers interviewed in Kathmandu and Biratnagar, out of more than 4000 PCL nurses produced every year, about more than 3000 come from the colleges/instates run by the private sector. Because nursing education sector is thought to be an attractive area for private investors, there is unhealthy completion among the private business people to acquire affiliation from the CTEVT. Some interviewee contended that the private business people who do not have adequate expertise to run a nursing education programme are also involved; as a result, there is a risk of the nursing education sector becoming an object of commercialisation.

\section{Quality and integrity}

Somewhat linked to the previous issue is the question of maintaining quality and integrity of the nursing education. Several interviewees mentioned that the overall quality of nursing education has declined recently, especially after the entry of the private sector in the nursing education business. One important aspect of maintaining quality in the nursing education is on-the-job practical training in which nurses learn care with mentors in hospitals and communities. However, during interviews it was learned that student in many nursing colleges in districts go for practicum in district level hospitals where there are not adequate patients for all students to serve. ${ }^{5}$

CTEVT has a monitoring system in place. An analysis of physical infrastructure, quality of hospitals where nurses will do practicum and human resources are taken into considerations before providing licence to

\footnotetext{
${ }^{5}$ Interview with a nurse teacher from Kathmandu.
} 
private institute to offer nursing education. But, according to an interviewee, in many private nursing institutes, the human resource mentioned on the approval paper and those working day-to-day basis are different.

\section{Lack of demand and supply analysis}

How many nurses does Nepal's health care system require? How many of them are required in rural areas and urban areas? These are important but unanswered questions. Despite more than 4000 PCL nurses produced every year, there is always scarcity of nurses in districts and remote areas. The fact that only 3000 nurses are currently working in the national health care system points towards a necessity for comparing and contrasting net demand and net supply ratio of nurses in the country. The nursing education sector is lucrative business, but what if people are investing money in nursing education while the national health care system is not able to absorb graduated nurses. Nursing education, after all, should not be a business profitable to few private sector people and a net loss to the nation, students and their parents. It is important to note here that the nursing education, provided by the government owned institutions/colleges under the IOM, TU are heavily subsided; therefore, the government is investing a huge amount of budget to produce nurses who may not get employment at the end of the day. Therefore, demand supply analysis of nursing professionals is highly important at present.

\section{Exploitation of newly trained nurses}

It has become increasingly difficult for newly graduated nurses to get job in the market. The reason is they lack experience. Ironically, the practicum they undertake during the nursing training is not considered as an experience in the health industry. As a result, a large number of fresh nursing graduates are either idle or undertake unpaid or partially paid volunteer jobs. During the fieldwork, I collected many complaints from newly graduated nurses about their difficulty to find job, but more importantly about their exploitations. For example, some nurses who were working as a volunteer were forced to work long hours. Others suffered from humiliation and discrimination in the work place. The list can go on and on; however the point here is transition to professional career for newly graduated nurses is extremely challenging and hard, with some being vulnerable to exploitation in the work place. In teaching practicum is counted as experience, it would reduce the chances of exploitation of newly trained nursed in the competitive health industry.

\section{Nursing: an accelerator of international migration}

According to the recent record of Nepal Nursing Council, ${ }^{6}$ there are around 30,000 nurses in the country. However, most of the graduate nurses either do not get the jobs, or stay in different employment sector. Families who can afford abroad migration invest in sending nurses to go abroad for further study. Different studies have shown that nurses constitute an important categories among those migrating to abroad for education and employment (Adhikari, 2009-2010; Subedi, 2012). It is estimated that in 2008 Nepal ranked fifth in the hierarchy of source countries of nurses to the UK, where between 800 and 1000 Nepali nurses are reported to work. The USA, the UK, Australia and Canada are top four countries that receive trained nurses from Nepal.

Although the migration of nursing is increasing exponentially, the Nepal Nursing Council record shows that a total number of 3461 nurses migrated abroad between 2002 and 2011. Some respondents believe that the number should be fairly higher than this because the Nursing Council data only show the nurse who migrated under skilled category. In fact, majority of nurse migrate abroad as a student; therefore they might not be necessarily accounted for in the council's record.

When asked why they choose to study nursing, an overwhelming number of student nurses mentioned that "they want to go abroad". Thus aspiration and dream to go abroad is the fundamental catalytic factor for students to choose nursing education. Subedi (2012) has further shown that there is also a trend in society that parents invest in relatively expensive nursing education for their daughters because of attractive possibility of sending their children to abroad.

Increasing demand of trained and educated nurses in developed countries like UK, USA, Australia and Canada has become motivating factor for young women to enter into the nursing career. Therefore, the demand abroad has become a catalytic factor for booming of nursing education industry in the country. This is a long distance transnational effect of global nursing care industry.

For those lucky nurses who are able to fund education and find jobs abroad, the booming nursing education industry in the country has proved a boon. Working as an immigrant nurses involves more complex forms of work place stressors due to cultural differences and new culture in the workplaces. It was further reported that immigrant nurses abroad experience typically different forms of workplace stressors that might even have effects on their personal lives. More importantly, being away from home and family, they might have been left with minimum support mechanisms to cope or recover from workplace stressors that a family could

\footnotetext{
${ }^{6}$ See http://www.nnc.org.np/
} 
extend. This is an area where more research is needed. The reality for those who are not able to migrate is not very encouraging. Either they are left with low paid jobs are even in many cases unemployment or underemployment is possible.

In the context of Nepal, abroad migration of nurses is considered to be brain drain(Sapkota, van Teijlingen, \& Simkhada, 2014). There will always be health worker emigration if government policies cannot address their individual, family and societal problems. An optimistic view in this regard is that there are some positive outcome for the sending country in terms of remittance and skill transfer (Sapkota et al., 2014). While international migration cannot be stopped in highly networked and globalised worked; it can only be managed and regulated in the favour of domestic economy and human capital accumulation. Therefore, migration of skilled workers is also thought to be unescapable "brain circulation" rather than "brain drain" in the contemporary world (Subedi, 2012). In the interviews, some held a pessimistic view viz a viz emigration of nurses is that the government is investing hugely in producing nurses for developed economies while the country still lacks nurses in rural areas. Addressing this pessimistic view requires a long term health policy that takes into account of actual demand of health professional in the country and designs policy that offers attractive incentives, lucrative career path and better social security. Unless these conditions are achieved, the country might be losing its young and dynamic nurses.

\section{Conclusions}

Using a qualitative method, this article has studied the historical trajectory of the growth of nursing education sector in Nepal. It has shown that the recent juncture, which is called, globalised period, has experienced a boom in the nursing education sector that has produced nurses in unprecedented scale. However, the growth has also met with some challenges. One of the challenges is not only privatisation, but also commercialisation of nursing education sector. As an immediate impact of commercialisation is the problem in maintaining quality and integrity of the nursing education sector. There is a need to make the nursing education more than "money making" business for some sector people and focus on maintaining world class quality among newly educated nurses. The other critical issue highlighted in this paper is lack of knowledge and awareness in health policy about the actual need versus current trend of supply of trained nurses in the country. This hits towards an immediate need for analysis of demand and supply ratio. The other critical issue is unemployment and exploitation of newly graduated nurses. Finally, the article has shown that on the one hand, boom in the nursing industry in the country is aiding to emigration of educated nurses. On the other hand, the demand of educated health professional in the global health sector has also played a catalytic role for people to invest in the nursing industry in a country like Nepal.

\section{References}

[1]. Adhikari, R. (2009-2010). The "dream-trap": Brokering, "study abroad" and nurse migration from Nepal to the UK. European Bulletin of Himalayan Research, 35-36, 122-138.

[2]. Boykin, A., \& Schoenhofer, S. (2001). The Role of Nursing Leadership in Creating Caring Environments in Health Care Delivery Systems. Nursing Administration Quarterly, 25(3), 1-7.

[3]. Dixit, H. (2005). Nepal's Quest for Health: Health services of Nepal Kathmandu: Educational Publishing House.

[4]. Gurung, G., \& Facchini, E. (2011, 22 December ). The nurses' dilemma, The Kathmandu Post.

[5]. Khanal, D. R., Rajkarnikar, P. R., Acharya, K. P., \& Upreti, D. R. (2005). Understanding Reforms in Nepal: Political economy and institutional perspective. Kathmandu: Institute for Policy Research and Development.

[6]. Sapkota, T. N., van Teijlingen, E., \& Simkhada, P. P. (2014). Nepalese health workers' migration to the United Kingdom: A qualitative study. Health Science Journal, 8(1), 57-74.

[7]. Sigdel, R. (2011). Nursing Education in Nepal: Historical Perspective. Health Prospect, 10, 89-90.

[8]. Subedi, D. B. (2012). From Student to Transnational Migrant: Paradigm shift in student migration from Nepal. Saarbrucken: Lambert Academic Publishing.

[9]. Thieme, S., \& Wyss, S. (2005). Migration patterns and remittance transfer in Nepal: A case study of Sainik Basti in western Nepal. International Migration, 43(5), 59-98.

[10]. WHO. (2003). The World Health Report 2003. Geneva: World Health Organisation 